\section{EREM 75/1}

Journal of Environmental Research, Engineering and Management

Vol. 75 / No. 1 / 2019

pp. 43-55

DOI 10.5755/j01.erem.75.1.21703
Model of Industrial Textile Waste Management

Received 2018/09
Accepted after revision 2019/03

\title{
Model of Industrial Textile Waste Management
}

\author{
Jovita Rapsikevičienė, Inga Gurauskienè, Agnè Jučienė
}

Institute of Environmental Engineering, Kaunas University of Technology, Gedimino St. 50. Kaunas, Lithuania

Corresponding author: Jovitasnk@gmail.com

J. Rapsikevičienè, Institute of Environmental Engineering, Kaunas University of Technology, Gedimino St. 50. Kaunas, Lithuania

Manufacturing of textile and apparel contributes depletion of water resources, the use of natural resources, the release of water and air pollution and increasing the amount of waste entering landfills. Industrial textile waste represents nearly half of the whole flow of textile waste. Major part of the industrial textile waste is landfilled, because of the lack of technologies and infrastructure for recycling. The practice of mixing all the textile cuttings at the apparel production companies, leads to the challenge for reuse or recycling of the leftovers.. Textile companies are obliged to look for alternative waste management options in order to meet the requirements and challenges of Circular Economy action plan published by the European Commission. This article represents the model created for the analysis of industrial textile waste flows and development of scenarios for reasonable waste management. The model and methodologies involved are oriented to preventive solutions -The evaluation of the efficiency of the model is based on sustainability indicators which represents the effect of the scenarios for environmental, economic and social aspects. The implementation of the model to the case study of Lithuanian apparel production company, have disclosed that improvements at the industrial textile waste management within the company, could lead to the increase of efficient use of resources (three times) and environmental impact (twice).

Keywords: industrial textile waste, model, of textile waste management scenarios, waste prevention, reuse, recycling.

\section{Introduction}

The textile industry is one of the largest and most complex manufacturing processes in the manufacturing industry (Srebrenkoska et al., 2014). Moving around the world, the lifecycle of clothing spans many phases from resource production and extraction, fiber and yarn manufacturing, textile manufacturing to apparel assembly, packaging, transportation and distribution and finally usage, recycling and ultimate 
disposal (Kozlowski et al., 2012). The current mode of fashion consumption is increasingly fast paced, and characterized by artificial newness disposable trends, and aesthetic fad with new styles rapidly introduced on to the market replacing the old and stimulating the perpetual desire for novelty and change among consumers (Joy, 2012; Ozdamar Ertekin and Atik, 2015). So, fashion is the driving force behind of textile sector, which is precisely because of its increased consumption, which increases the amount of waste, as old products are converted to new ones. No longer used products are disposed into the landfills and such behavior is having the effect for relatively large volumes of waste from the textile industry. Textile wastes (including pre-consumption (waste generated during production and retail process) and after consumption (used textile) account around 5.8 million tons in the European Union annually. Only 1.5 million tones (25\%) of all textile waste are recycled. Remaining textile waste ( 4.3 million tons) are disposed into landfills or incinerated (Briga, 2013). As a result, it is now a widely held belief that this commonplace problem requires increased attention and innovative initiatives to remedy the current systemic inefficiencies that by default diverts large amount of used clothing and textiles to landfills (Hvass 2014). There are many investmens in research to find the right combination of textile materials, development of new products and technologies. The use of new technologies that reduce environmental pollution, energy saving, and waste reduction is necessary because of the negative impact on the environment done by the textile industry (Mileriene 2014). This industry is one of the industries with the largest recycling potential and innovative recovery, upcycling innovations, but it is not exploited enough:

If the fashion industry wants to achieve the highest and most effective level of waste management - prevention, then the formation of fabric scraps should be decreased at the design stage. Disposal of fabric scraps during design process is zero waste modeling.

Creative recycling is a new concept for many manufacturers, designers and users and it helps to find effective solutions to gain added value at the recycling of waste. Such kind of ideas can be a good starting point for small businesses, because they do not re- quire special skills, without major investment in production (Milerienè 2014).

Textile wastes that are unsuitable for reuse can be recycled using mechanical, biological, chemical, thermal or all-together technologies.

Only textile waste that are unsuitable for recycling or incineration can be disposed landfill. The amount of textile waste, which is disposed in the landfills, can be reduced in accordance with the following hierarchical scheme - oriented to sustainable textile resource and its waste management (see Fig. 1.).

\section{Fig. 1}

The Waste Hierarchy (EU Waste Framework Directive, 2008).

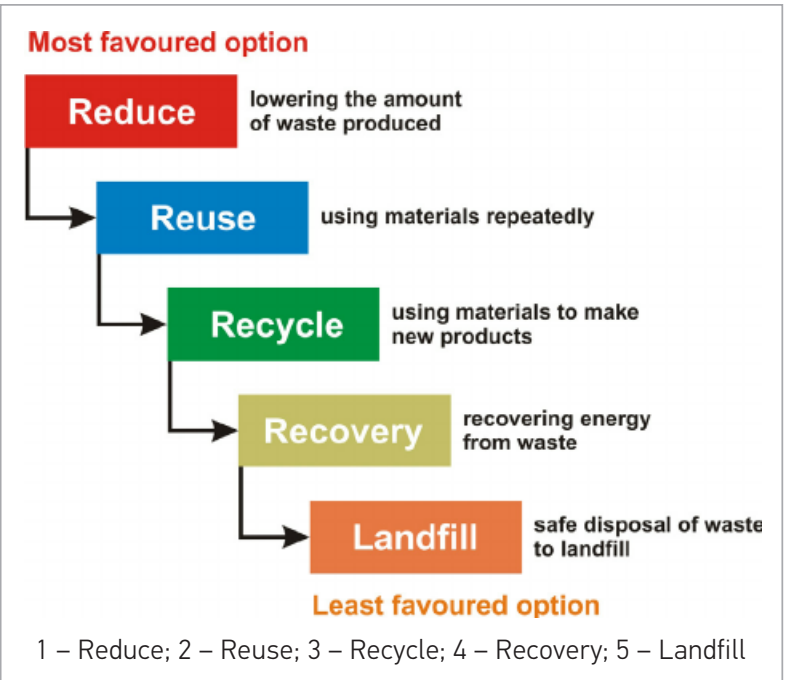

It is evaluated that by cutting and sewing of textiles, approximately 15 percent of the fabric is disposed of to the landfill but could be reused. Direct reuse keeps materials at an equal or higher quality and requires less energy as an input than recycling, while prevention and reduction decreases the creation of waste and need for additional resources and energy overall (Danielle 2017). According to numerous sources extending the useful life of a garment/textile has been found to greatly decrease environmental aspects demonstrated over its entire lifetime, including its embedded energy, carbon footprint, and water use, among other (Farrant et al., 2010, Watson et al., 2014, Roos et al., 2015, Roos 2016, Schmidt et al., 2016). In this article describes other ways (reuse, prolonging of 
thelifespan and material recycling) in order to avoid disposal to the landfill and thus not losing the value. In this article, the possibility is considered to create a circle management system of industrial textile, including the use of waste, creating product of high or a higher value-added as the complex of different options The aim of the research was to evaluate the flows of textile scraps in the textile apparel manufacturing company, to propose scenarios for the reuse and recycling of industrial textile waste, based on hierarchy of waste management. Based on the research results the model is created and presented in this paper as the tool for other textile companies, while selecting the most appropriate and sustainable options for industrial textile waste (pre-consumption textile waste, or cut offs of textile) management.

\section{Methods}

Analyzed the textile company is a world - class garment and furniture manufacture company based in Scandinavia (Denmark), Europe (Lithuania) and Asia (Vietnam). Selected for research a textile factory which is in Lithuania. The designing, cutting and sewing of clothing is performed in this textile factory.

The amount of waste generated over the whole year $(\mathrm{t} ; \mathrm{kg})$, is calculate according the (Mileriene and Dobilaite, 2014) methodology and the data of textile company.

BMrATS = BMrS - GMS;

Where: BMrATS - the amount of waste generated over the whole year $(\mathrm{t} ; \mathrm{kg})$.

$\mathrm{BMrS}=\sum_{i=1}^{n} \mathrm{MrSi}$

Where: BMrS - total weight of the substance concerned $(\mathrm{t} ; \mathrm{kg}), \mathrm{MrS1}, \mathrm{MrS2}, \ldots \mathrm{MrSn}$ - the weight of each roll material $(\mathrm{t} ; \mathrm{kg})$, weight indicated on the roll material labels (weight without sticks of packing).

GMS $=\sum_{i=1}^{n} B G M r S i$

Where: GMS - the total quantity of materials cut into the product by the company $(\mathrm{t} ; \mathrm{kg})$.

$B G M r S i=G M r S n{ }^{*} G K n$;
Where: BGMrSi - total weight of parts for one order ( $\mathrm{t} ; \mathrm{kg}) ; \mathrm{GMrSn}$ - the weight of the piece cut from one type of material from the corresponding type of material (t; $\mathrm{kg}) ; G K n$ - amount of the details of the order (pieces).

The weight per $\mathrm{m}^{2}$ of the material is calculated knowing material length $(\mathrm{m})$ in the roll, the width $(\mathrm{m})$ and weight ( $\mathrm{t}$ ) (given on the label of the material).

Weight $_{(1 \mathrm{~m} 2 \text { of material) }}=$ weight / (length * width) $(t)$;

Knowing how much weighs $1 \mathrm{~m}^{2}$ of material, all the data receive in tonnes are converted to $\mathrm{m}^{2}$.

Categories of textile scraps are important for scenarios of waste management. The scraps are fractionate according to length and width. Size of scraps is measured in the following way: scraps are divided into regular rectangles; length and width of are measured; scraps fractionate according their length $(\mathrm{cm})$ and width $(\mathrm{cm})$ into small, medium small and large categories (see Table 1). The categories are selected according to the dimensions and them quantities of all scraps.

$S_{\text {material }}=$ width * length * number of layers ${ }^{1}\left(\mathrm{~m}^{2}\right)$;

$S_{\text {total area of scraps }}=S_{\text {small scarps }}+S_{\text {medium small scarps }}+$ $+S_{\text {large scarps }}\left(\mathrm{m}^{2}\right)$

Where: $S$ - area

Areas of small, medium small and large scraps calculated as $\mathrm{m}^{2}$ need to be converted to percentage, $\%$.

$\begin{array}{ll}\mathrm{S}_{\text {total area of scraps }} & -100 \% \\ \mathrm{~S}_{\text {small/ medium small/ large scraps }} & -\mathrm{x} \%\end{array}$

Table 1

Categories of scraps size

\begin{tabular}{c|c|c|}
\hline Width of scraps, $\mathrm{cm}$ & Length of scraps, $\mathrm{cm}$ & Category \\
\hline 1 & 2 & 3 \\
\hline $1-3$ & {$[1-3]-200$} & Small \\
4 & $4-99$ & \\
\hline 4 & $100-200$ & \\
$5-8$ & {$[5-8]-200$} & Medium \\
9 & $9-200$ & \\
\hline 10 & $10-200$ & Large \\
\hline
\end{tabular}

${ }^{1}$ Material prepared for cutting 
Software - STAN (Software for substance flow analysis) ${ }^{2}$ is used for material flow analysis (MSA) for representation of textile waste flows in the analysed company and for comparison of current situation and situation based on the recommended waste management scenarios. The STAN software helps to identify input and export flows, demonstrate production processes and possible waste management scenarios and defined scoring limits.

Methodology of indicators is used to evaluate environmental and economic impact of textile flows determined by waste management scenarios.

The environmental indicators are developed based on the waste management hierarchy. The principle of waste hierarchy ${ }^{3}$ is provenand broadly used for waste and resource management. The following coeficients to different waste management options have been attributed at this research in order to make the quantitative evaluation of waste management option. Each category of the hierarchical scheme is assimilated to a certain coeficient (1-5), whereas 1 - represents the most environmentaly favorable option, and 5 - the worst option (see Fig.1.). The offered scenarios of waste management are expressed as percentage and are assigned for specific category of the hierarchical scheme. If the number of resulting indicators is closer to the unit 1 , the waste management option is more environmentally friendly.

Scenario of prevention is calculated as follows:

All scraps \% / PCWM (see Fig. 1.) = 1/1

Where: PCWM - the prevention category of waste management

Scenario of reuse is calculated as follows:

All scraps \% / RCWM (see Fig. 1.) = 1/2

Where: RCWM - the reuse category of waste management

Recent environmental indicator of analyzed textile company is calculated as follows:

\footnotetext{
2 http://www.stan2web.net/

${ }^{3}$ https://wastelessfuture.com/ad-lansink-waste-hierarchy-stimulates-circular-economy/
}

$(S L \% / D C W M)+(S E \% / R C W M)$ (see Fig. 1.) $=$ $=(S L \% / 5)+(S E \% / 2)$

Where: SL - the scraps that is disposal to landfill; DCWM - the disposal category of waste management; SE - the scraps that is donating for educational companies; RCWM - the reuse category of waste management.

The environmental indicator of the created model by recommended waste management scenarios is calculated as follows:

$(S N P \% / R C W M)+(S R E \% / R E C W M)($ see Fig. 1.) $=$ $=(S N P \% / 2)+(S R E \% / 3)$

Where: SNP - the scraps that is proposed for the development of new products; RCWM - the reuse category of waste management; SRE - the scraps that is recycle; RECWM - the recycling category of waste management.

Economic value was calculated based on the evaluation of lost value:

(CRM (Eur) - CRMP product (Eur)) + WMC (Eur) $=$ = Lost value of scraps (Eur);

Where: CRM - Costs of raw material; CRMP - Cost of raw material for product; WMC - Waste management costs.

The lost value of scraps after implementation of the created model:

$(C R M(E u r)-C R M P(E u r)-C R M A(E u r))+W M C($ Eur $)=$ = Lost value of scraps (Eur);

Where: CRM - Costs of raw material; CRMP - Cost of raw material for product; CRMA - Cost of raw material for additional products; WMC - Waste management costs.

\section{Results and Discussion}

The methodology has been verified at the selected textile processing company producing different clothes for international markets. Analysis has been made based on the data of year 2016. There was used $283,592.11 \mathrm{~m}^{2}$ of different fabrics. $76 \%$ of textile has 
been used for products, and $24 \%$ of material - cutoffs become as textile waste. The composition of fabrics, distribution of products and waste streams are presented in Fig. 3. It figures out the composition of fabrics, distribution of products and waste streams in analyzed company.

Fig. 3

Textile flows within the company, 2016

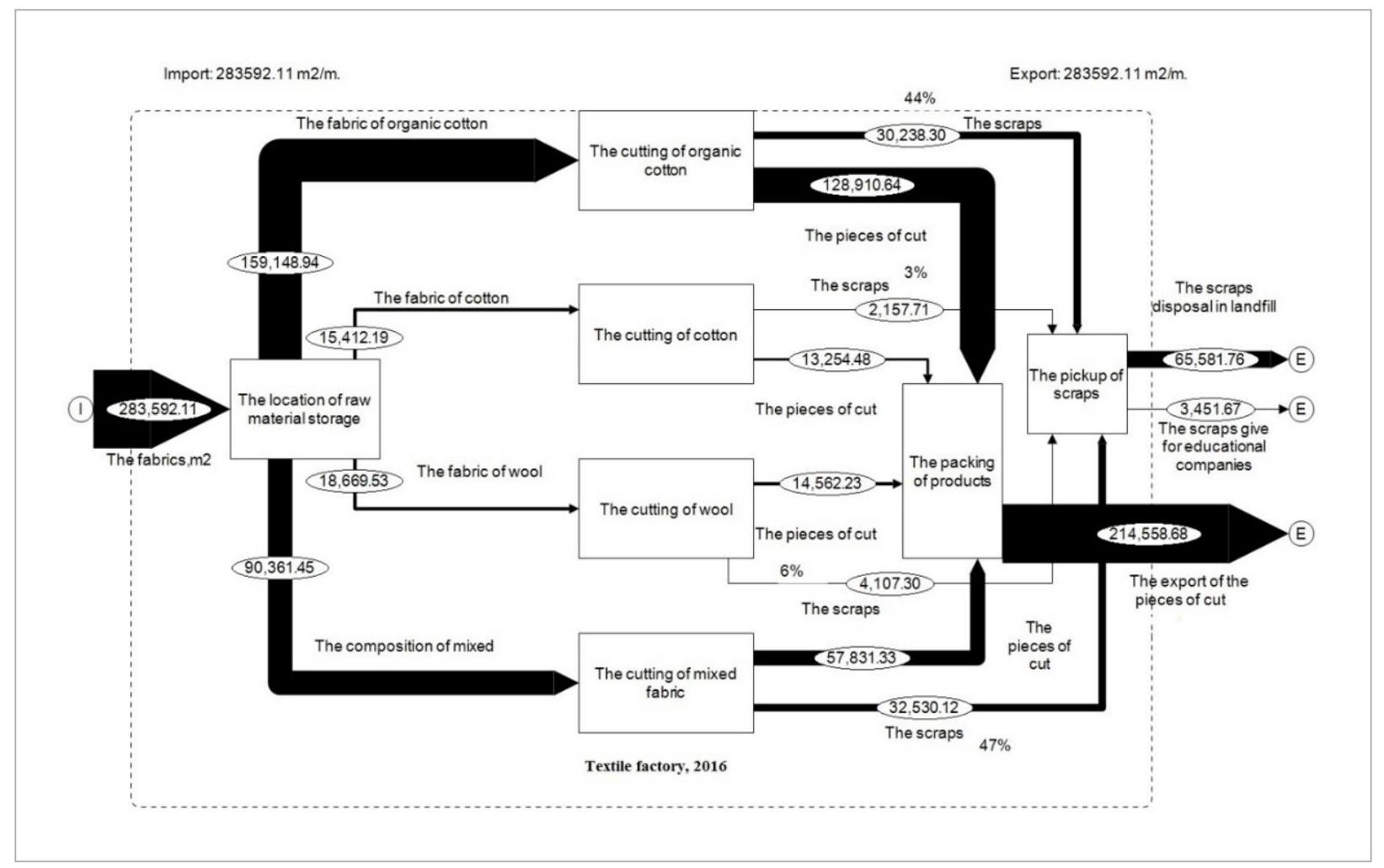

Most of all products was made from organic cotton $60 \%$ and mixed fabric - $27 \%$ in the selected textile company in 2016. The greatest share of textile waste is out of mixed material $-47 \%$ and organic cotton $44 \%$, wool and cotton waste all together accounted for $9 \%$. The amount of textile waste depends on the form and size of the pieces to be cut. The share of the textile waste by the size is shown in Fig. 4.

The length $(\mathrm{m})$ and width $(\mathrm{m})$ of mixed textile waste were measured and fractionated into categories: small, medium and large. The analysis has been based on the experiment made with mixed composition textile as the amount of this garment was largest in 2016. The whole area of fabric was $319.28 \mathrm{~m}^{2}$, and area of measured scraps was $114.46 \mathrm{~m}^{2}$ what
Fig. 4

The share of scraps of textile by the size

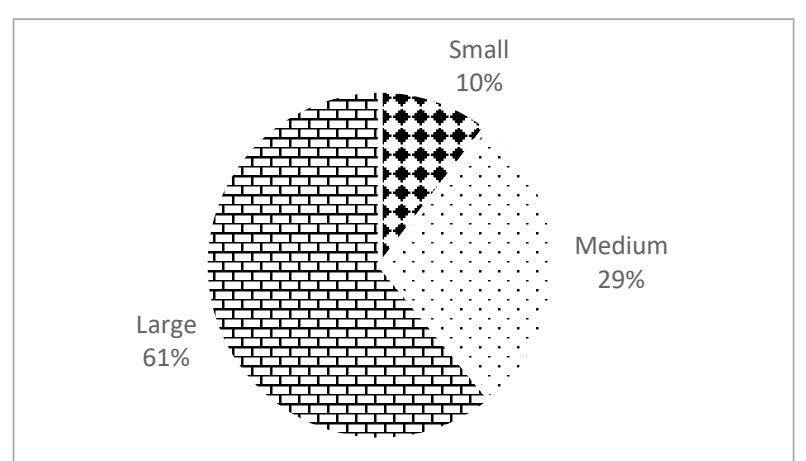

accounts for $36 \%$ of the total fabric. The small scraps accounted $10 \%$, medium $29 \%$ and large $61 \%$ of all 
the scraps. It was assumed that other fabrics (cotton, organic cotton and wool) has the same share of the scraps. Based on the literature analysis (Briga et al., 2013, Rissanen 2013, Milerienè 2014, Bianca 2015, Newell 2015, Zero Waste 2016), composition and size of the resulting scraps of textiles is the main outcome for creation of scenarios for textile waste management. Scenarios are being created according hierarchical waste management scheme.

Scraps of mixed textile were formed $32,530.12 \mathrm{~m}^{2}$ (assuming small and medium scraps were $39 \%$, large $61 \%)$ in the analyzed textile company. The waste

Fig. 5

The flows of the mixed fabric scraps based on the waste management scenarios

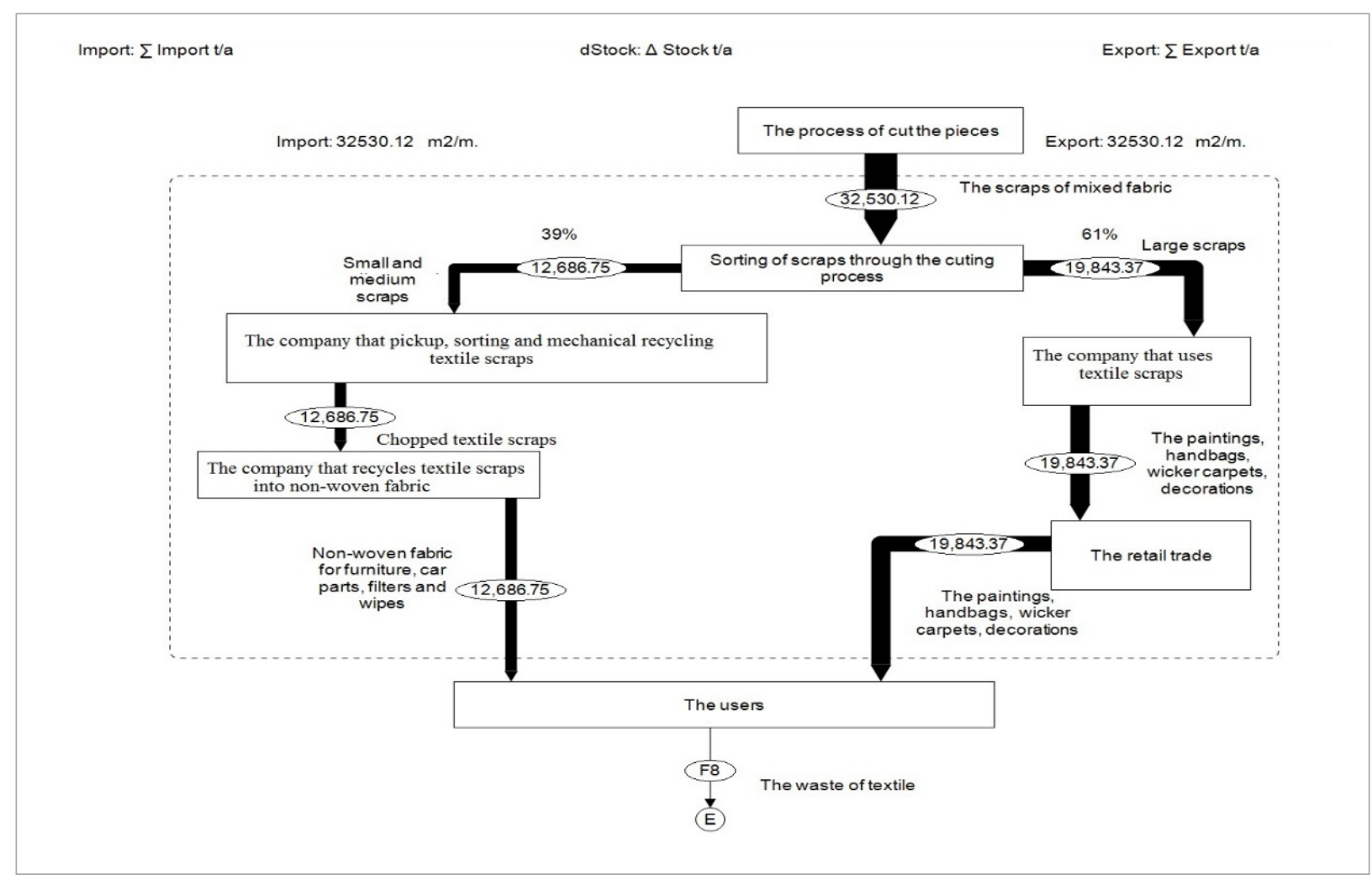

management scenarios are represented by the flows of mixed textile scraps in Figure 5. Two scenarios created for the scraps. One flow indicates that small and medium scraps of mixed textile are directed to recycling company, where the pickup, sorting and mechanical recycling of textile waste is done. Then chopped textile scraps is targeted to the company recycling scraps into non-woven fabric. Non-woven fabric is used for production of furniture, car parts, filters and wipes. The second flow show that large scraps of mixed textile is targeted to company, making new items from textile scraps.
Scraps of organic cotton textile - 30,238.3 $\mathrm{m}^{2}$ (whereas small scraps $-10 \%$, medium and large $-90 \%$ ). Three waste management scenarios are created for these scraps (presented in Fig. 6). The first scenario shows that small scraps are used for compost production, the second - small scraps is targeted to company, which makes products of non-woven fiber. The third flow show that medium and large scraps of organic cotton fabric is targeted to company, where textile scraps are used for making new items. Organic cotton scraps are used to make for cosmetic napkins, children's clothing and accessories. 
Fig. 6

The flows of the organic cotton scraps based on the proposed waste management scenarios

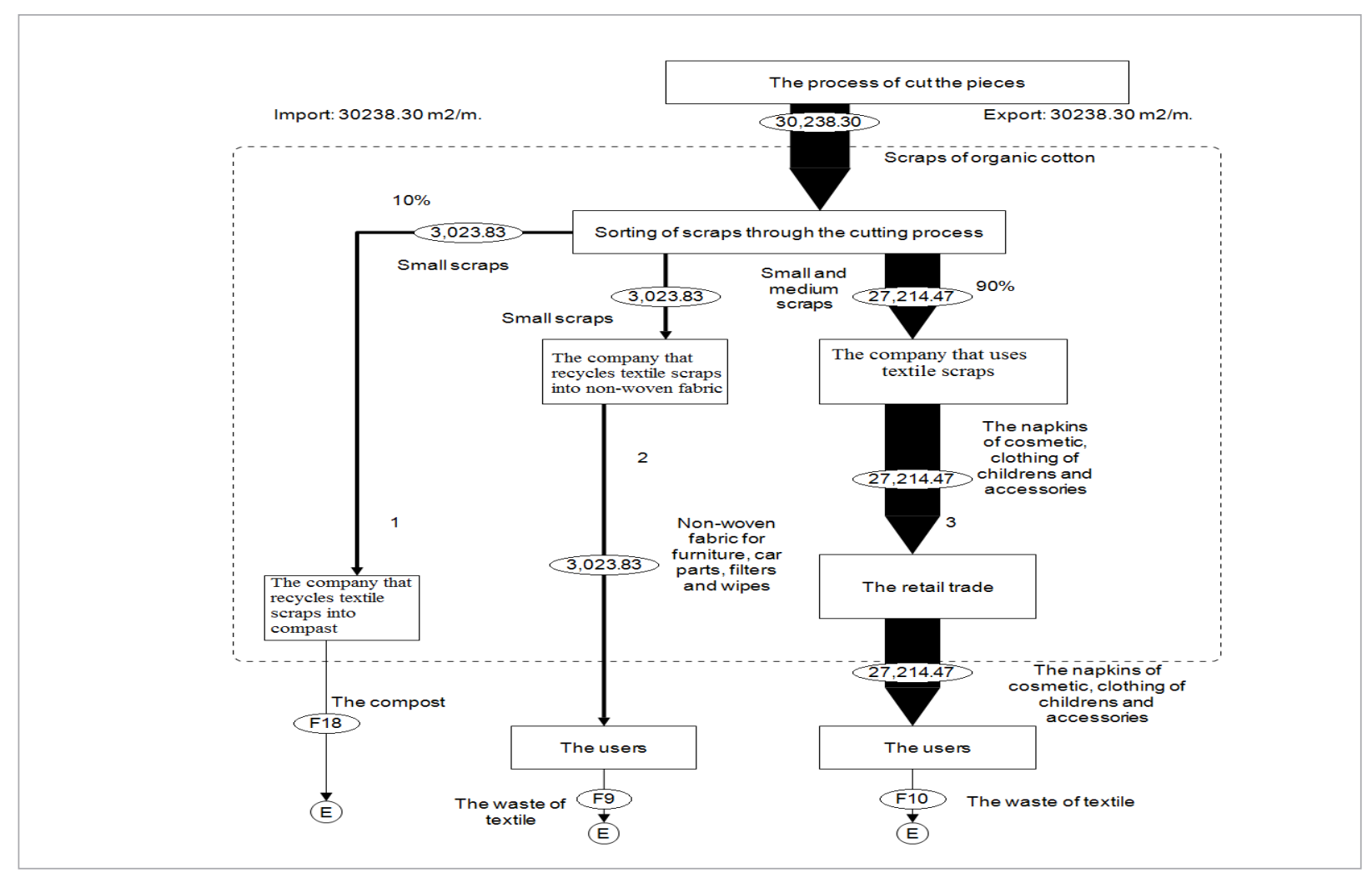

Scraps of cotton textile $-2,157.71 \mathrm{~m}^{2}$ (small scraps $10 \%$, medium and large $-90 \%)$. Three scenarios are created for these scraps and its flows presented in Fig. 7. One flow indicates that small scraps of cotton are targeted to company, which makes a compost, while the other flows indicate that small scraps can be directed to company recycling scraps into non-woven fiber. Medium and large scraps are transferred to company using textile scraps as material for production of new items. Cotton scraps are used to make clothes for animals, bed linen and chair linen and bags, which can be sold to the retail market.

Scraps of wool textile $-4,107.3 m^{2}$ (small scraps - 10\%, medium and large - 90\%). Two scenarios created for these scraps and flows of wool textile scraps are presented in Fig. 8. One flow indicates that small scraps are transfer to the company recycling scraps into non-woven fiber, other flow shows that medium and large scraps are transfered to company, producing new items. Wool textile scraps can be used for manufacture of jewelry, children's felts, scarf, and felt blankets.

Analysis of the scenarios. Five scenarios of textile waste management were selected for analyzing the textile company (see Fig. 9.). Based on the scenarios there has been indicated the need to sort scraps into 5 separate containers: 1 - medium and large scraps of organic cotton and cotton; 2 - small scraps of organic cotton and cotton; 3 - scraps of wool textile; 4 - large scraps of mixed textile; 5 - medium and small scraps of mixed textile. Waste of the second container (more than $5 \%$ of all the company's scraps) will be delivered directly to compost company (see Fig. 9.). Textile waste of the first (organic cotton and cotton) and the fourth (mixed) container would be transferred to company, which makes textile products from scraps. This would account for $71 \%$ of the total 
Fig. 7

The flows of the organic cotton scraps based on the proposed waste management scenarios

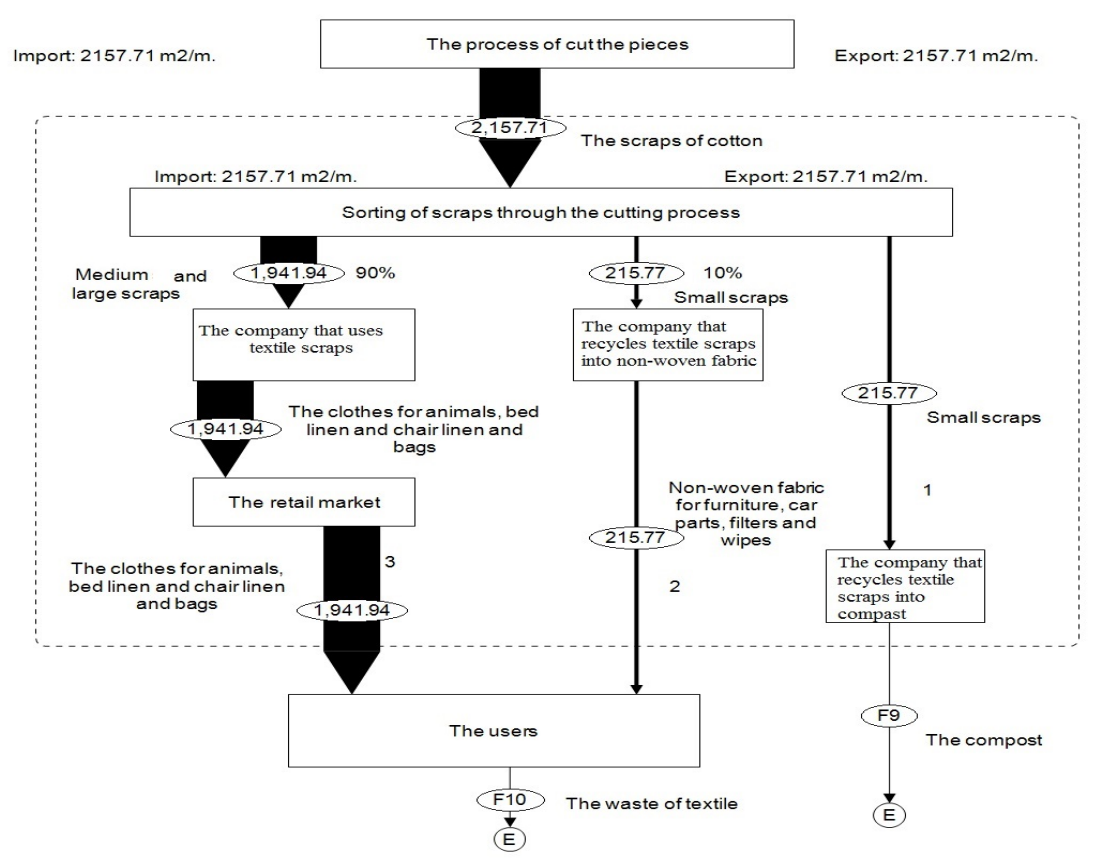

Fig. 8

The lows of the wool scraps

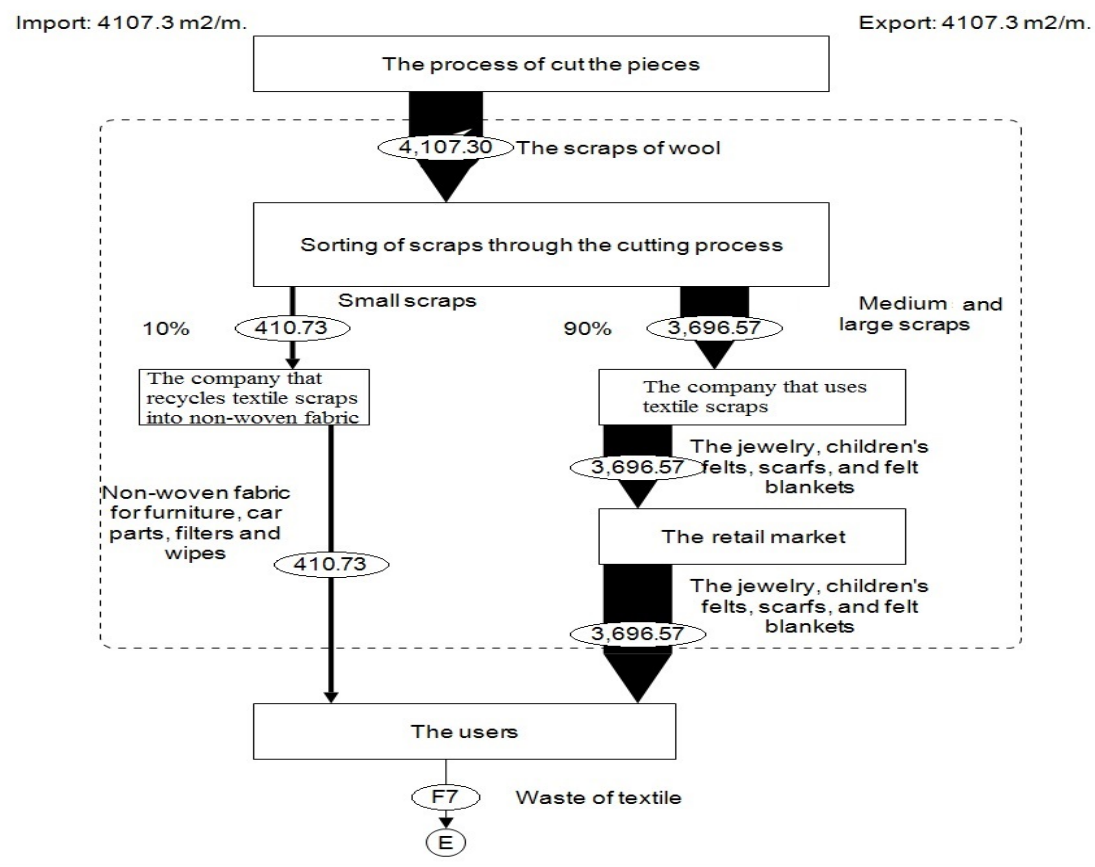


Fig. 9

All the developed textile waste management scenarios integrated into the company

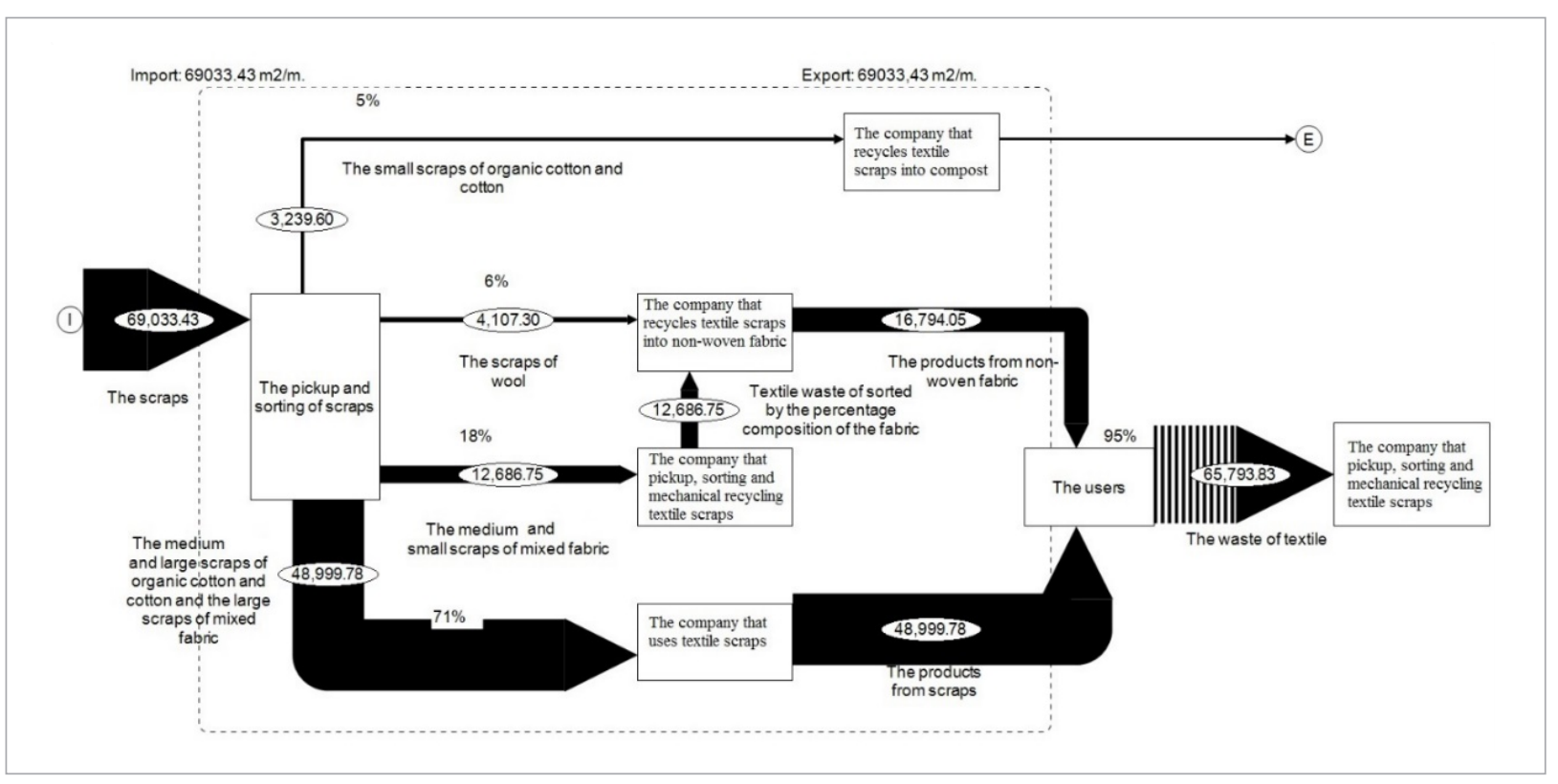

Fig. 10

The model for industrial textile waste management

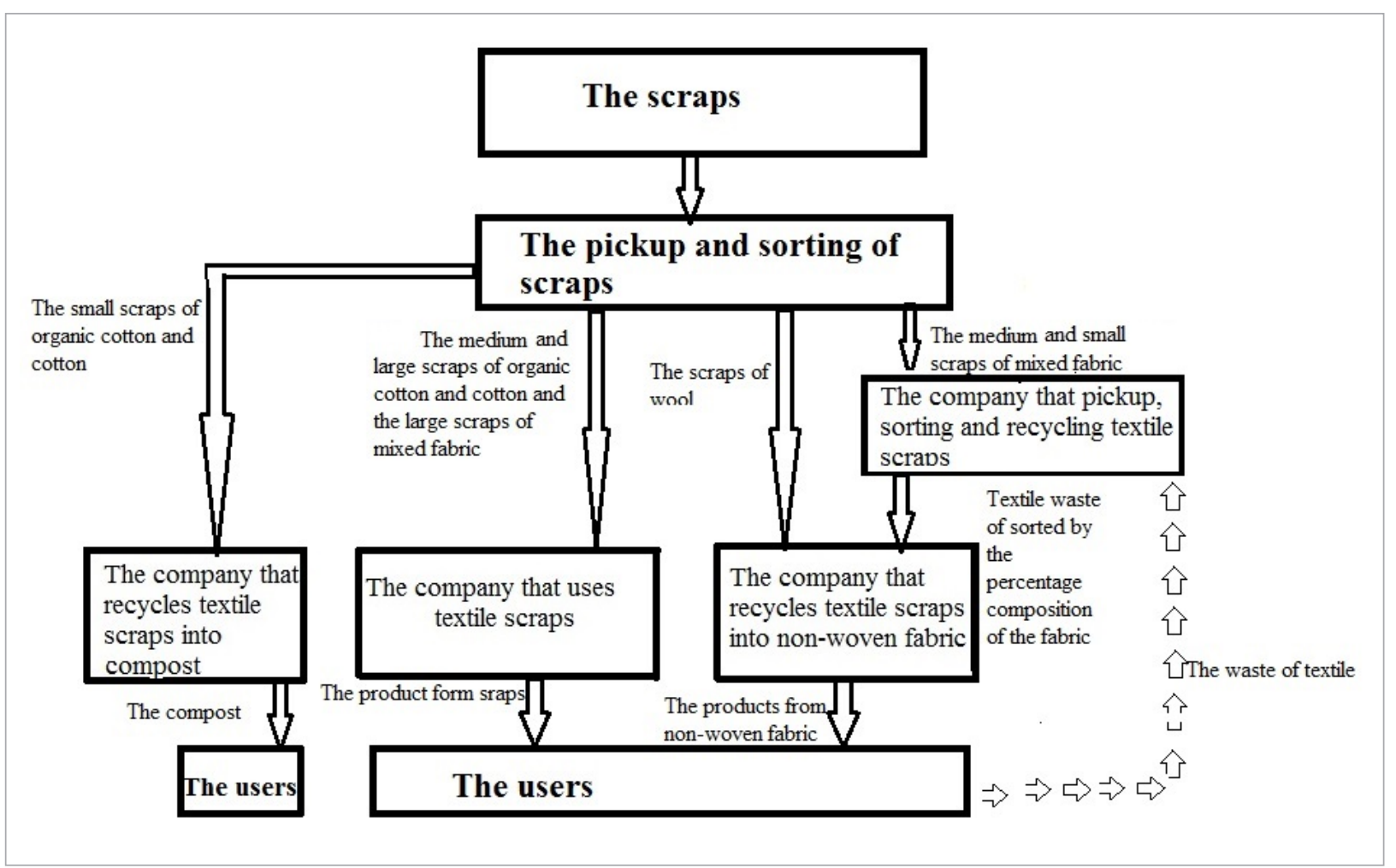


textile cuttings of the company. The wool scraps (account for $6 \%$ of the total textile waste) collected in the third container. These scraps would be transferred to the company which recycled scraps into non-woven materials. Scraps of the fifth (mixed textile waste) container would be directly transferred to the recycling company. Scraps is sorted and handed over to the processing company according to their specific properties (see Fig. 9). Altogether, 18\% of all textile scraps would be transferred to the recycling company (see Fig. 9). Dotted line of figure 9 shows possible flows end of use textile products.

Analysis of textile scraps and their use scenarios allow the creation a model of textile waste management that can be applied to many textile companies (see Fig. 10). The composition and the size of the fabrics, environmental indicators, the literature analysis and the company interests were extremely important for a model creation.

Developed model (see Fig. 10) is based on the decision making process how to manage the textile waste produced in the apparel production company. This model could be used as guidelines for other textile companies, in order to make identification, evaluation of textile flows and to develop waste management scenarios in the particular region. There is foreseen that every company oriented to the more environmentally friendly waste management, need to integrate preventive measures (design), and sorting of generated scrap as well. The amount of sorting categories depends on the market where the scraps are planned to be realized (reuse, recycling, upcycling, composting and etc.). There is planned that sustainable management of post-consumer items also need to be integrated in the value chain of the textile production.

\section{Assessment of waste management scenarios and model}

The assessment of the proposed waste management scenarios and the model integrating the selected scenarios is evaluated based on the sustainability indicators expressed as value.

Environmental Value. From an environmental perspective, the value of a created model is relatively high. The analyzed textile company $95 \%$ of scraps (mixed materials, organic cotton, cotton and wool) disposes to landfill and $5 \%$ is given to educational companies. Environmental value calculated based on formula 13 is $0.19 \%$. The proposed waste management scenarios leads to the increase of environmental value until $0.5 \%$.

This model supports one of the basic tenets of the Circle Economy, Principle 2, to circulate products, components, and materials at their highest utility at all times (Foundation 2015). It is also considered ideal from the perspective of the waste hierarchy with direct reuse and longer lifespans for textile products demonstrating the greatest energy and $\mathrm{CO}_{2}$ equivalent savings(Farrant et al., 2010, Fisher et al., 2011, Morley 2013, Laitala 2014, Cooper 2016).

Social Value. Social value is created with the creation of employment opportunities, infrastructure development, and increased social welfare from a reduction in textile waste disposal. Social value is expressed as creation of employment opportunities, development of infrastructure, and increased social welfare because of reduction in textile waste disposal. Creation of small businesses using textile waste as resources is another and very important social benefit(Sarkis et al., 2011, Nikolaou et al., 2013, Schenkel et al., 2015).

Economic Value. The lost value of resources because of scrap generated in the company is equal $376,627.15$ Eur and after implementation of scenarios is evaluated the decrease until 131,628.25 Eur.

\section{Fig. 11}

Impact of proposed model for the textile waste management based on the waste management hierarchy

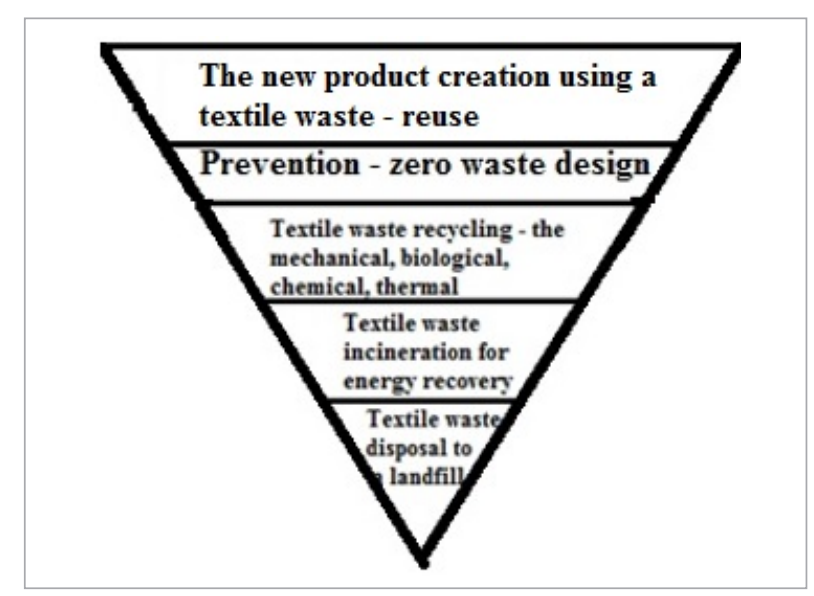




\section{Table 2}

The comparison of different alternatives for management of manufacturing textile waste

\begin{tabular}{|c|c|c|c|c|}
\hline & Current situation & Zero waste & Reuse & $\begin{array}{l}\text { Application of the model, } \\
\text { according to the created } \\
\text { scenarios }\end{array}$ \\
\hline 1 & 2 & 3 & 4 & 5 \\
\hline $\begin{array}{l}\text { Environmental } \\
\text { benefit }\end{array}$ & $\begin{array}{l}\text { Industrial textile } \\
\text { landfilled }\end{array}$ & $\begin{array}{l}\text { prevention of textile } \\
\text { resource loss and waste } \\
\text { generation }\end{array}$ & $\begin{array}{l}\text { Reuse of textile scrap } \\
\text { convert waste into } \\
\text { resources }\end{array}$ & $\begin{array}{l}\text { Reduces production of } \\
\text { industrial textile waste }\end{array}$ \\
\hline $\begin{array}{l}\text { Economic } \\
\text { benefit }\end{array}$ & Loss of raw materials & $\begin{array}{l}\text { Avoidance of raw materials } \\
\text { loss }\end{array}$ & $\begin{array}{l}\text { Added value for the textile } \\
\text { scraps }\end{array}$ & $\begin{array}{l}\text { Reduced amount of } \\
\text { raw materials lost. } \\
\text { Added value }\end{array}$ \\
\hline Social benefit & $\begin{array}{l}\text { negative effect is not } \\
\text { evaluated at present }\end{array}$ & Development of creativity & $\begin{array}{l}\text { Additional staff required, or } \\
\text { cooperation with the social } \\
\text { companies. Positive impact } \\
\text { for social groups outside } \\
\text { the company }\end{array}$ & $\begin{array}{l}\text { Increase creativity, } \\
\text { engagement and } \\
\text { positive social benefit }\end{array}$ \\
\hline $\begin{array}{l}\text { Viability in the } \\
\text { industry }\end{array}$ & $\begin{array}{l}\text { Activities as usual - } \\
\text { oriented to the final } \\
\text { product. Most of } \\
\text { the business and } \\
\text { manufacturing } \\
\text { companies apply } \\
\text { this model. }\end{array}$ & $\begin{array}{l}\text { It is possible to apply } \\
\text { for small businesses or } \\
\text { companies which orients } \\
\text { their production explicitly to } \\
\text { the zero waste design (one } \\
\text { of the main criterions in the } \\
\text { design process) }\end{array}$ & $\begin{array}{l}\text { Additional efforts are } \\
\text { needed to create sub } \\
\text { products from the scraps, } \\
\text { or cooperation with other } \\
\text { companies }\end{array}$ & $\begin{array}{l}\text { Demand for additional } \\
\text { premises, equipment, } \\
\text { competencies and } \\
\text { investments }\end{array}$ \\
\hline
\end{tabular}

The whole impact of the model is complex and qualitative evaluation is as important as quantitative ones., where the different alternatives of manufacturing textile waste management compared with the current situation in the table presented below (Table 2).

The hierarchical diagram below shows how this model would change the management of industrial textile waste (see Fig. 11). At present, most of the textile waste is disposed to the landfill, and after implementation of a model, the scraps are oriented for secondary usage creating new products, reusing the generated scraps. Prevention is being carried out in companies nowadays, relatively large companies use efficient material cutting programs while relatively small ones are trying to use zero waste modeling (Zero Waste 2016, Danielle 2017).

\section{Conclusions}

Textile industry has a large potential of waste recycling and reuse, however analyses of scientific literature disclose that the greatest share of industrial textile waste is disposed at landfills. The research described at this paper is based on the garment production company and the data of 2016. The amount of textile waste generated at the company is $24 \%$ of the total amount raw materials (textile) used. Industrial textile waste is uncontaminated and relatively clean to be used to create a new product or to be recycled. Analysis disclosed main aspects which could lead to unsustainable waste management: company oriented to the production of final product and textile waste is considered as the problem not opportunity; textile waste (scrap) is not sorted and almost the all quantity (95\%) is disposed into landfills. Based on the results of the current situation 3 scenarios have been proposed for more environmental friendly waste management: 1. zero waste when all fabric is used for product details, according to the need to change their dimensions; 2. reuse when scraps are directed to company, that to make a new item. 3. Scraps are directed to the recycling companies. As the final result model for industrial textile waste management has been created. The model integrates: analysis of 
the composition of the fabrics, production processes and material flows within the company, the literature analysis for each textile composition and the company interests based on the market and possible technological possibilities. The evaluation of the efficiency of the model has disclosed that it has positive impact for all the sustainability aspects: environmental (increase

\section{References}

Bianca, B. (2015). Retraço Novo: Moda sustentável. http://biancabaggio.com.br/projeto_retraco_novo/.

Briga, S. á., b A., NascimentoaD., TeixeiraaN.,Pintoa, cJ., CaldeiradF.,VarumeH., (2013). Textile waste as an alternative thermal insulation building material solution. Construction and Building Materials Volume 38. 155 - 160. https://doi.org/10.1016/j.conbuildmat.2012.08.037

Cooper, T. E. (2016). Longer lasting products: alternatives to the throwaway society.CRC Press. https://doi. org/10.4324/9781315592930

Danielle, A. (2017). All you have to do is ask: Innovation and value creation in the postconsumer apparel industry. IIIEE, Lund University, P.O. Box 196, S-22100 LUND, Sweden.

Farrant, L., Olsen, S. I., \& Wangel, A. (2010). Environmental benefits from reusing clothes. The International Journal of Life Cycle Assessment, 15(7). 726-736. https://doi.org/10.1007/ s11367-010-0197-y

Fisher, K., James, K. \& Maddox, P. (2011). Benefits of Reuse Case Study: Clothing. WRAP, Banbury.

Foundation, E. M. (2015). Towards a circular economy: Business rationale for an accelerated transition.

Hvass, K. K. (2014). Post-retail responsibility of garments-a fashion industry perspective. Journal of Fashion Marketing and Management, 18(4). 413-430. https://doi.org/10.1108/JFMM01-2013-0005

Joy, A., Sherry Jr, J. F., Venkatesh, A., Wang, J., \& Chan, R. (2012). Fast fashion, sustainability, and the ethical appeal of luxury brands. Fashion Theory, 16(3). 273-295. https://doi.org /10.2752/175174112X13340749707123

Kozlowski, A., Bardecki, M., \& Searcy, C. (2012). Environmental impacts in the fashion industry: A life-cycle and stakeholder framework. The Journal of Corporate Citizenship, (45), 17. https://doi.org/10.9774/GLEAF.4700.2012.sp.00004

Laitala, K. (2014). Consumers' clothing disposal behaviour-a synthesis of research results. International Journal of Consumer Studies, 38(5): 444-457. https://doi.org/10.1111/ijcs.12088 in 2,5 times), economic value increased three times and social benefit is foreseen for the company (increasing amount of the working places) and having external positive social impact outside the company. The created model could be transferred and adapted for other textile manufacturing companies, based on the methodology described in this paper.

Milerienè, G. (2014). Gamybinių tekstilès atlieku panaudojimo galimybès.

Morley, N. (2013). Closing the loop for clothing: closed loop fibre recy- cling - current status and future

Newell, A. S. (2015). Textile waste resource recovery: a case study of New York State's textile recycling system. A Thesis Presented to the Faculty of the Graduate School Cornell University In Partial Fulfillment of the Requirements for the Degree of Master of Arts.

Nikolaou, I. E., Evangelinos, K. I., \& Allan, S. (2013). A reverse logistics social responsibility evaluation framework based on the triple bottom line approach. Journal of Cleaner Production, 56. 173-184. https://doi.org/10.1016/j.jclepro.2011.12.009

Ozdamar Ertekin, Z., \& Atik, D. (2015). Sustainable markets: Motivating factors, barriers, and remedies for mobilization of slow fashion. Journal of Macromarketing, 35(1). 53-69. https:// doi.org/10.1177/0276146714535932

Rissanen, T. (2013). Zero - waste fashion design - a study at the intersection of cloth, fashion design and pattern cutting.

Roos, S. (2016). “Advancing life cycle assessment of textile products to include textile chemicals. ." Inventory data and toxicity impact assessment (Doctoral dissertation, Chalmers University of Technology).

Roos, S., Sandin, G., Zamani, B., \& Peters, G. (2015). Environmental assessment of Swedish fashion consumption. Five garments-sustainable futures. Mistra Future Fashion. Management for Social Innovation of the Textile Sector.

Sarkis, J., Zhu, Q., \& Lai, K. H. (2011). An organizational theoretic review of green supply chain management literature. International Journal of Production Economics, 130(1). 1-15. https://doi.org/10.1016/j.ijpe.2010.11.010

Schenkel, M., Krikke, H., Caniëls, M. C., \& van der Laan, E. (2015). Creating integral value for stakeholders in closed loop supply chains. Journal of Purchasing and Supply Management, 21(3). 155-166. https://doi.org/10.1016/j.pursup.2015.04.003

Schmidt, A., Watson, D., Roos, S., Askham, C., \& Poulsen, P. B. (2016). Gaining benefits from discarded textiles: LCA of different 
treatment pathways. Nordic Council of Ministers. https://doi. org/10.6027/TN2016-537

Srebrenkoska, V., Zhezhova, S., Risteski, S., Saska, G. (2014). Methods for waste waters treatment in textile industry. International scientific konference 21-22.
Watson, D., N. Kiørboe, D. Palm, H. Tekie, S. Harris, T. Ekvall, T. Lindhqvist and K.A. Lyng (2014). EPR systems and new business models: reuse and recycling of textiles in the Nordic region.Temanord Report for the Nordic Council of Ministers.

Zero Waste, S. (2016). Waste Management Hierarchy. http://www. zerowaste.sa.gov.au/aboutus/waste-management-hierarchy. 